\title{
A Method to Calculate Adherence to Inhaled Therapy that Reflects the Changes in Clinical Features of Asthma
}

\author{
Imran Sulaiman \\ Royal College of Surgeons in Ireland, Dublin, Ireland \\ Jansen Seheult \\ University of Pittsburgh Medical Center, Pittsburgh, PA \\ Elaine MacHale \\ Royal College of Surgeons in Ireland, Dublin, Ireland
}

See next page for additional authors

Follow this and additional works at: https://arrow.tudublin.ie/engschmanart

Part of the Biomedical Engineering and Bioengineering Commons

\section{Recommended Citation}

Costello RC.et al. (2016) A Method to Calculate Adherence to Inhaled Therapy That Reflects the Changes in Clinical Features of Asthma. Ann Am Thorac Soc, 2016. doi:10.1513/AnnalsATS.201603-2220C

This Article is brought to you for free and open access by the School of Manufacturing and Design Engineering at ARROW@TU Dublin. It has been accepted for inclusion in Articles by an authorized administrator of ARROW@TU Dublin. For more information, please contact arrow.admin@tudublin.ie, aisling.coyne@tudublin.ie, gerard.connolly@tudublin.ie.

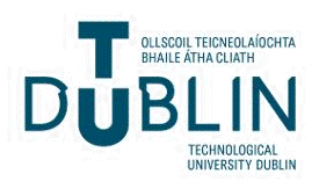




\section{Authors}

Imran Sulaiman, Jansen Seheult, Elaine MacHale, Fiona Boland, Susan M. O'Dwyer, Viliam Rapcan, Shona D'Arcy, Breda Cushen, Matshediso Mokoka, Isabelle Killane, Sheila A. Ryder, Richard B. Reilly, and Richard W. Costello 


\title{
A Method to Calculate Adherence to Inhaled Therapy that Reflects the Changes in Clinical Features of Asthma
}

\author{
Imran Sulaiman ${ }^{1,2}$, Jansen Seheult ${ }^{3}$, Elaine MacHale ${ }^{2}$, Fiona Boland ${ }^{4}$, Susan M. O’Dwyer ${ }^{5}$, Viliam Rapcan ${ }^{2}$, \\ Shona D'Arcy ${ }^{2}$, Breda Cushen ${ }^{1}$, Matshediso Mokoka ${ }^{1}$, Isabelle Killane ${ }^{2}$, Sheila A. Ryder ${ }^{5}$, Richard B. Reilly, 6,8, \\ and Richard W. Costello $1,2,9$
}

${ }^{1}$ Department of Respiratory Medicine, ${ }^{2}$ Clinical Research Centre, ${ }^{4}$ Population Health Sciences, and ${ }^{9}$ Department of Medicine, Royal College of Surgeons in Ireland, Dublin, Ireland; ${ }^{3}$ Special Chemistry Division, Department of Pathology, University of Pittsburgh Medical Center, Pittsburgh, PA; 5 School of Pharmacy and Pharmaceutical Sciences, ${ }^{6}$ Trinity Centre of Bioengineering, 7 School of Medicine, and ${ }^{8}$ School of Engineering, Trinity College, The University of Dublin, Dublin, Ireland

ORCID ID: 0000-0003-1992-0280 (I.S.).

\begin{abstract}
Rationale: Currently, studies on adherence to inhaled medications report average adherence over time. This measure does not account for variations in the interval between doses, nor for errors in inhaler use.
\end{abstract}

Objectives: To investigate whether adherence calculated as a single area under the (concentration-time) curve (AUC) measure, incorporating the interval between doses and inhaler technique, was more reflective of patient outcomes than were current methods of assessing adherence.

Methods: We attached a digital audio device (INhaler Compliance Assessment) to a dry powder inhaler. This recorded when the inhaler was used, and analysis of the audio data indicated if the inhaler had been used correctly. These aspects of inhaler use were combined to calculate adherence over time, as an AUC measure. Over a 3-month period, a cohort of patients with asthma was studied. Adherence to a twice-daily inhaler preventer therapy using this device and clinical measures were assessed.

Measurements and Main Results: Recordings from 239 patients with severe asthma were analyzed. Average adherence that was based on the dose counter was $84.4 \%$, whereas the ratio of expected to observed accumulated AUC, actual adherence, was $61.8 \%$ $(P<0.01)$. Of all the adherence measures, only adherence calculated as AUC reflected changes in asthma quality of life, $\beta$-agonist reliever use, and peak expiratory flow over the 3 months $(P<0.05$ compared with other measures of adherence).

Conclusions: Adherence that incorporates the interval between doses and inhaler technique, and calculated as AUC, is more reflective of changes in quality of life and lung function than are the currently used measures of adherence.

Clinical trial registered with www.clinicaltrials.gov (NCT 01529697).

Keywords: asthma; inhaler; adherence; clinical outcomes

(Received in original form March 30, 2016; accepted in final form July 6, 2016)

Supported by the Health Research Board (CSA12/19, HRA-POR-2011-59, and DI-59) and from GlaxoSmithKline Global.

Author Contributions: E.M., S.M.O'D. and S.A.R. were involved primarily in patient recruitment; S.D'A., V.R., I.K., and R.B.R. were involved primarily in the audio analysis; F.B. was involved primarily in the statistical analysis; B.C. and M.M. were involved in data collection and data analysis; I.S., J.S., and R.W.C. were involved in all aspects required for this manuscript, including patient recruitment, data management, and data analysis, and were the primary leads in the design of the work; and all authors were involved in writing and editing this manuscript.

Correspondence and requests for reprints should be addressed to Richard W. Costello, M.D., Royal College of Surgeons in Ireland, Beaumont Hospital, Dublin 9, Ireland. E-mail: rcostello@rcsi.ie

Ann Am Thorac Soc Vol 13, No 11, pp 1894-1903, Nov 2016

Copyright @ 2016 by the American Thoracic Society

DOI: 10.1513/AnnalsATS.201603-2220C

Internet address: www.atsjournals.org

Electronic monitors are considered the gold standard for objectively quantifying adherence to inhaled therapy (1). Most studies using electronic recording devices have reported adherence as the mean adherence, or the mean daily dose, over the study period (2-4). However, this method does not reflect variations in the way that patients use their treatments. For example, the mean adherence is the same whether an individual took the medication according to the prescribed schedule or took all the doses in the first half of a dosing period, leaving none in the second half. Inhaler technique must be included in the 
assessment of adherence because an individual may use his/her inhaler according to the dosing schedule but with incorrect technique, resulting in no medication being delivered. In this case, the average use over time is meaningless unless data on the technique of use are also incorporated into the calculation of adherence. Most electronic recording devices do not assess whether the inhaler was used correctly (5-12). Hence, there is a need to develop a method to quantify adherence that accounts for variations in dosing schedules as well as inhaler user technique.

We developed a device, INhaler Compliance Assessment (INCA), which makes a digital file each time the inhaler is used (13). Analysis of this information means that the time of use, the interval between doses, and the proficiency of the inhaler use can be assessed (13). Technique errors identified by this method include failing to prime the inhaler, dispersing the medication by exhalation into the inhaler after priming, and dose dumping $(14,15)$. In addition, the acoustic features of inhalation are highly reflective of objectively measured peak inspiratory flow, meaning that the device can estimate the peak inspiratory flow at each inhalation (16), (17).

The aim of this study was to test the hypothesis that by including the time of use, the interval between doses, and the inhaler technique, we could quantify adherence as an area under the curve (AUC) and, furthermore, determine whether adherence calculated using AUC was more reflective of patient outcomes than the current methods of assessing adherence. Some of the results of this study have been reported previously in the form of an abstract (18).

\section{Methods}

\section{Study Design}

Patients for this study were prospectively recruited from five specialty asthma clinics in Ireland from January 2011 to December 2015. Participants included in this analysis include all patients with asthma studied to date, both those who participated in the pilot preliminary study $(\mathrm{n}=32)$ and those from the single, blind, prospective, multicenter, randomized controlled clinical trial $(n=207)$ that followed. The full protocol of the study has already been published (19). All patients from both groups of the randomized control trial were combined to provide at least 6,000 audio files for analysis (50\% of prescribed inhalations over the month for 200 patients).

On enrolment, the patients were shown how to use the inhaler, and errors were corrected using a 10-point checklist inhaler proficiency score (20-22). Over the following months $(4,8$, and $12 \mathrm{wk})$, the patients returned to the clinic, where inhaler technique was checked and improved if necessary, and adherence was encouraged.

The primary end point of this study was to describe inhaler adherence using a new method of calculating adherence and its relationship with clinical outcomes in asthma, such as quality of life, disease control, and lung physiology.

\section{Participants}

Inclusion criteria were patients who were $\geqslant 18$ years of age who had already been prescribed therapy equivalent to step 3 or higher in the Asthma Management Guidelines $(23,24)$ and who, in addition, had had at least one exacerbation treated with systemic glucocorticoids in the previous year. The dose of inhaled corticosteroid and long-acting $\beta$-agonist was not changed during the study. Exclusion criteria included an unwillingness to participate in a clinical study or prior hypersensitivity to salmeterol/fluticasone. Asthma diagnosis was made using a clinician diagnosis supported by one or more of the following: obstructive spirometry with at least $12 \%$ reversibility, a positive bronchial provocation challenge, or variability in the diurnal peak expiratory flow (PEF) of $>15 \%$. All patients provided written informed consent. The study was approved by local hospitals' ethics committees.

\section{Electronic Adherence Monitor}

We have reported previously the development and validation of the INCA audio recording device in 60 patients with a total of 1,200 audio recordings (13). The device contains a microphone, internal clock, battery, and memory card with plastic housing. It is attached to an inhaler and records the audio associated with an individual using his/her inhaler (Figure 1). In previous studies, we have shown that

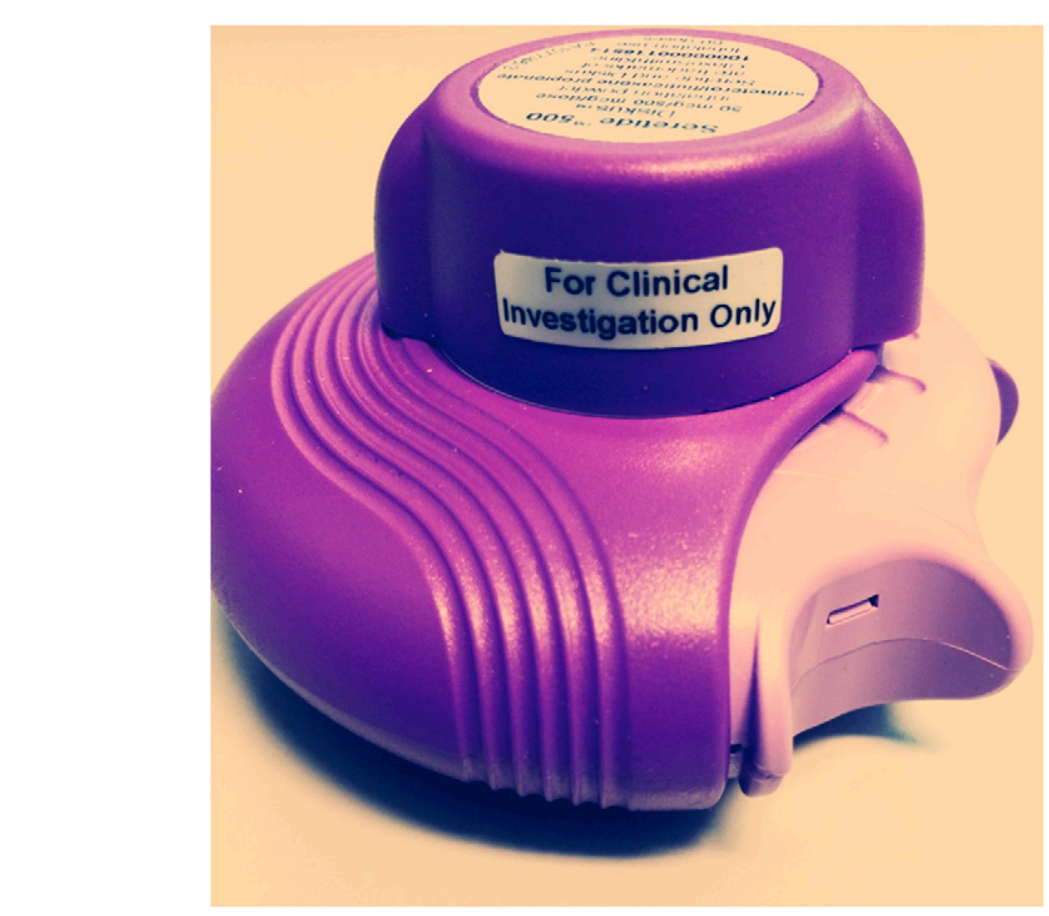

Figure 1. Photograph of the INhaler Compliance Assessment (INCA) device attached to a salmeterol/ fluticasone Diskus inhaler. The device contains a microphone, an internal clock, a memory card, and some circuitry. Every time the inhaler device is opened, the INCA starts recording audio of the patient using his/her inhaler with a date-time stamp. 
A
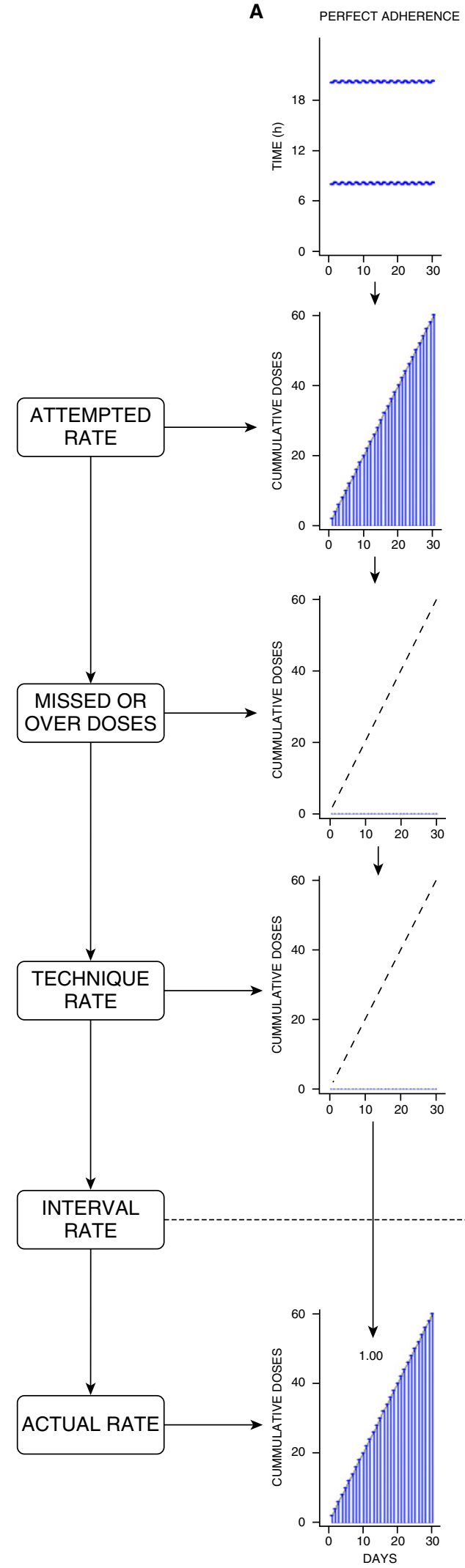

B MISSED DOSES
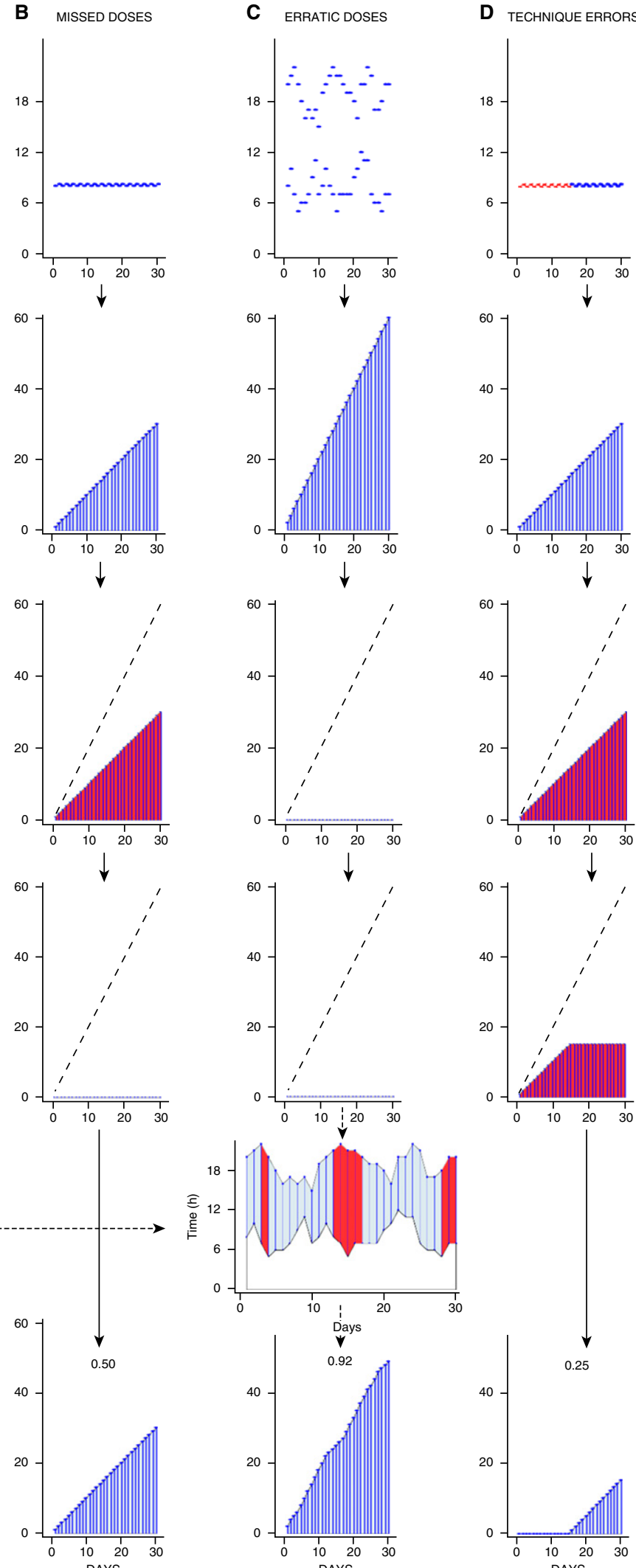

Figure 2. Calculation of adherence algorithm. Examples of patients prescribed a medication twice daily for 30 days are shown. Column $A$ is an example of a patient with perfect adherence over a 30-day period. Attempted adherence, $f(\mathrm{AT})$, is perfect, 60 doses taken over 30 days. There were no missed doses 
inhaler errors such as low inspiratory flow and exhalation into the inhaler are identified easily. We have also shown that the acoustic features of inhalation are directly proportional to peak inspiratory flow $(14,16$, $17)$. The device has a failure rate of $<2 \%$; it was developed at the Trinity Centre of Bioengineering, Dublin, and is Conformité Européene (CE) marked and manufactured by Vitalograph Ltd., Ennis, Republic of Ireland. The device is currently available for use in research. Participants in this analysis received an INCA-enabled salmeterol/ fluticasone Diskus inhaler each month.

\section{Extraction of Features of Inhaler Use and Calculating Adherence}

Audio raters assessed each acoustic

recording for evidence of critical errors, as described previously (13-15). Critical errors in inhaler use, such as low inspiratory flow, were classified as no dose, whereas noncritical errors, such as vertical position of the inhaler, were classified as a complete dose.

The interval between doses was calculated on the basis of drug half-life, and the measurement of doses taken was related to this drug interval (for this study, the pharmacokinetic profile and drug half-life of salmeterol were used). A dose taken within one half-life of the drug, after the previous dose, was counted as one dose. When the interval between doses was greater than one half-life and less than two half-lives, this was considered 0.5 dose. In cases in which the interval between doses was greater than four half-lives, this was considered no dose. Information collected on the time, the interval between doses, and the technique of inhaler use was combined to calculate an AUC metric. Initially, the AUC is calculated for the expected doses, denoted by $f(\mathrm{ex})$. After this, the AUC is calculated for the participant's attempted dosing, denoted by $f($ at). Attempted dosing refers to the number of doses that patients attempt to take (i.e., evidence of drug priming in the acoustic analysis; these doses may be taken correctly or incorrectly) and was used to calculate the attempted adherence, $f(\mathrm{AT})$.

Attempted adherence $f(\mathrm{AT})=f($ at $) / f($ ex $) \%$

This value, relative to the expected doses, $f(e x)$, gives information on overdosing, denoted by $f(\mathrm{od})$ and missed doses, denoted by $f(\mathrm{md})$. By removing doses where a critical error has occurred, the actual doses, denoted by $f(\mathrm{ad})$, may be deduced. Subtracting this value from $f(\mathrm{AT})$ gives us the technique rate, denoted by $f($ te $)$.

Technique rate $f(\mathrm{te})=f(\mathrm{AT})-f(\mathrm{ad})(\%)$

The interval adherence $f(\mathrm{i})$ is calculated as the ratio of the attempted interval adherence $f$ (iat) to the expected interval adherence $f$ (iex).

Interval adherence $f(\mathrm{i})=\frac{f(\text { iat })}{f(\text { iex })}(\%)$

Furthermore, by removing the technique errors, we can calculate the actual adherence $f(\mathrm{AC})$.

Actual adherence $f(\mathrm{AC})=f(\mathrm{i})-f(\mathrm{te})(\%)$

See Figure 2 for a graphical display of this process and for a definition of terms.

\section{Analysis of PEF}

A similar method to that described above was used to analyze PEF data. Expected PEF was calculated on the basis of age, sex, and height.

AM PEF AUC $f(\mathrm{AM})=\frac{f(\text { Recorded AM PEF })}{f(\text { Expected AM PEF })}(\%)$

PEF variability (25) was calculated as the difference between A.M. and P.M. PEF AUC.

$$
\text { AM PM variability } f(\mathrm{AMPM})=f(\mathrm{AM})-f(\mathrm{PM})(\%)
$$

\section{Outcome Measures}

At the end of each month, the INCA device was collected from the participant. Audio
Table 1. Baseline characteristics of the study population

\begin{tabular}{lc}
\hline $\begin{array}{l}\text { Baseline } \\
\text { Characteristic }\end{array}$ & $\begin{array}{c}\text { Study } \\
\text { Population }\end{array}$ \\
No. patients & 239 \\
Age, yr & $49 \pm 16.1$ \\
Male sex, No. (\%) & $91(38)$ \\
FEV, L/s & $2.2 \pm 0.88$ \\
FEV 1 \% predicted & $74.1 \pm 22.9$ \\
No. exacerbations in & $4.3 \pm 3.5$ \\
the previous year & $12.2 \pm 4.5$ \\
ACT V1 & $3.9 \pm 1.3$ \\
AQLQ V1 & \\
Patients' reliever use, & \\
$\quad$ No. (\%) & $49(21)$ \\
Never & $15(6)$ \\
<1/wk & $8(3)$ \\
1/wk & $22(9)$ \\
2-5/wk & $145(61)$ \\
Every day & \\
\hline
\end{tabular}

Definition of abbreviations: ACT = Asthma Control Test (at visit 1); $A Q L Q=$ Asthma Quality of Life Questionnaire (at visit 1).

Data are presented as mean \pm SD unless otherwise stated.

data were downloaded from each device to provide information on inhaler use for the previous month. Additional information recorded at each visit included the findings of the Asthma Quality of Life Questionnaire (AQLQ) and the Asthma Control Test (ACT), the patient's self-reported reliever medication use, $\mathrm{PEF}$, and any recent exacerbations. Change in AQLQ $(26,27)$ was divided into those who did (improvers) and did not (nonimprovers) have an improvement of 0.5 points (the minimal clinically important difference in AQLQ). Change in PEF was also categorized into improvers and nonimprovers on the basis of a $10 \%$ cutoff $(23,24)$.

\section{Statistical Analysis}

Descriptive statistics were used to present basic patient details for those included in this analysis. Means and SDs are presented for continuous variables, and frequencies and percentages for categorical variables.

Figure 2. (Continued). and no technique errors, the interval between doses is within one half-life, and the actual adherence rate, $f(A C)$, is 1.00 (100\%). Column $B$ is an example in which the medication was taken only once daily for 30 days. The attempted adherence, $f(A T)$, is half that of column $A$ and there were 30 missed doses over 30 days. In this example, there were no technique errors. Because of missing doses every day, the interval between doses was also poor and $f(\mathrm{AC})$ is 0.50 (50\%). Column $C$ is an example of a patient who takes the medication (with no technique errors) every day, twice a day, but with erratic timing. There was perfect attempted adherence, with no missed doses and no technique errors. Because of the erratic time of use, for some doses that have an interval beyond the half-life of the drug, $f(i)$, the $f(A C)$ is reduced to 0.92 ( $92 \%$ ). Finally, column $D$ is an example of a patient who takes the medication only once daily and makes a technique error for the first 15 days of the 30 days. Therefore, the $f$ (AT) is half that expected (50\%) because of the 30 missing doses. There were also 15 doses with technique errors, and because of missing doses, every day the interval between doses was poor; therefore, the $f(\mathrm{AC})$ is $0.25(25 \%)$. 
Table 2. Mean adherence for all patients as calculated using different adherence measures

\begin{tabular}{ll}
\hline $\begin{array}{l}\text { Adherence } \\
\text { Measure }\end{array}$ & Mean \pm SD \\
\end{tabular}

Actual adherence $f(A C)$

Average adherence from dose counter* Mean daily dose Attempted adherence* $f($ AT $)$ Missed dose rate $f(\mathrm{md})$

Overdose rate $f(\mathrm{od})$

$61.8 \pm 28.5$

$84.4 \pm 19.1$

$85.0 \pm 21.3$

$79.4 \pm 20.7$

$20.7 \pm 18.7$

$6.6 \pm 9.2$

Technique error rate $f($ te $)$

${ }^{*}$ The difference in the average adherence by dose counter and attempted adherence is caused by multiple blisters and some unrecorded dose counters.

For each patient and each month of data, the following adherence measures were calculated: dose counter (average adherence), mean daily dose, $f(\mathrm{md}), f(\mathrm{od})$, $f(\mathrm{AT}), f(\mathrm{te})$, and $f(\mathrm{AC})$. Baseline adherence measures at Month 1 were

examined initially. We used $t$ tests to compare the means of these different adherence rates. Proportions were compared using a $\chi^{2}$ analysis. Over the 3 months, differences in adherence measures and associations with clinical outcomes were examined using an ordinary least-squares regression. Each adherence measure regression coefficient was compared with $f(\mathrm{AC})$ for improvers and nonimprovers separately. To compare these coefficients, a test of linear hypothesis after estimation was used, to determine if the linear expressions were equal.

Because there is no gold standard for calculating adherence, a sensitivity analysis was done by categorizing adherence into good and poor on the basis of an $80 \%$ cutoff for each adherence measure. With this categorization, each adherence measure's sensitivity and specificity at identifying improvers and nonimprovers (AQLQ and PEF) and controlled and uncontrolled (ACT) are reported. All statistical analysis was conducted using Stata Release 13

(StataCorp, College Station, TX).

\section{Results}

\section{Participants}

The clinical characteristics of the 239 participants included in this analysis can be seen in Table 1 . The patient cohort was primarily female $(62 \%)$ with a mean (SD) age of 49 (16.1) years. A large proportion of patients in this cohort had poorly controlled asthma, with a mean AQLQ of 3.9 and ACT of 12.2, and 145 patients $(61 \%)$ used a short-acting $\beta$-agonist on a daily basis.

\section{Baseline Adherence to Inhaled Therapy}

In the first month, there were 11 device failures $(<6 \%)$, 5 devices $(<3 \%)$ were lost, and a further six patients $(<3 \%)$ had missing dose counter information. For the first month, the total number of audio files with evidence of drug priming was 7,973 ,

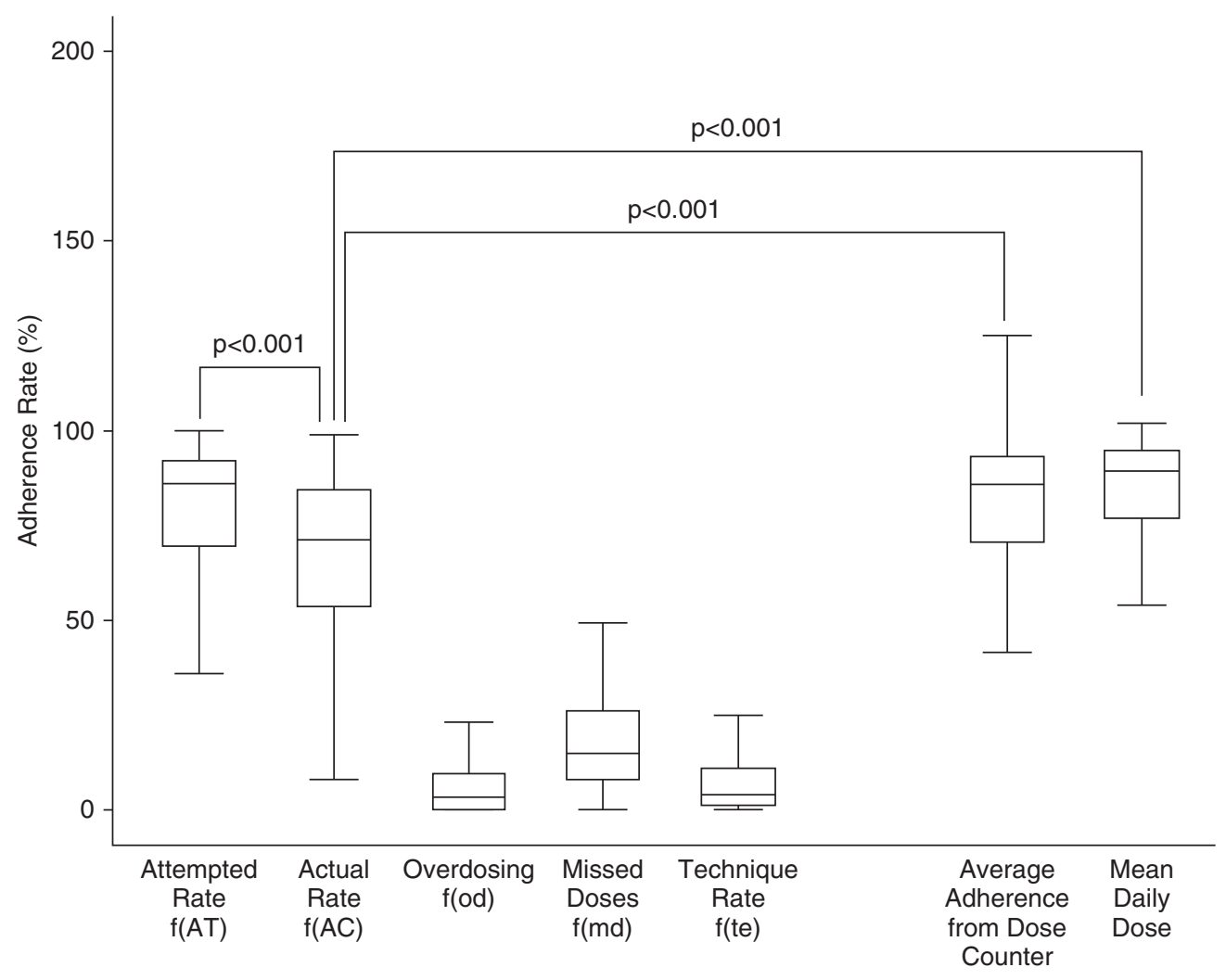

Figure 3. Graphical representation of adherence calculated in a number of ways. The data used for this graph are the first month's inhaler use by a cohort of 217 (of 239) patients with asthma enrolled in a prospective adherence intervention clinical study who were asked to use a dry powder inhaler twice daily. The actual adherence rate, $f(\mathrm{AC})$, is significantly different from the adherence calculated using the current methods, that is, average adherence from the dose counter and the mean daily dose, and the attempted rate, $f(\mathrm{AT})$ (the electronic time of use measure) $(P<0.001)$. 
Table 3. Patients considered adherent using various measures of adherence, with $80 \%$ as a cutoff for good and poor adherence

\begin{tabular}{|c|c|c|c|c|}
\hline \multirow{2}{*}{$\begin{array}{l}\text { Adherence } \\
\text { Measure }\end{array}$} & \multicolumn{2}{|c|}{ Good Adherence ( $>80 \%$ ) } & \multicolumn{2}{|c|}{ Poor Adherence ( $\leqslant \mathbf{8 0} \%)$} \\
\hline & $\mathbf{n}$ & Mean \pm SD (\%) & $\mathbf{n}$ & Mean \pm SD (\%) \\
\hline $\begin{array}{l}\text { Actual adherence } f(A C) \\
\text { Average adherence from } \\
\text { dose counter }\end{array}$ & $\begin{array}{r}67 \\
153\end{array}$ & $\begin{array}{l}90.9 \pm 4.5 \\
93.4 \pm 12.0\end{array}$ & $\begin{array}{r}156 \\
64\end{array}$ & $\begin{array}{l}49.3 \pm 25.1 \\
62.9 \pm 15.6\end{array}$ \\
\hline $\begin{array}{l}\text { Mean daily dose } \\
\text { Attempted adherence } f(A T)\end{array}$ & $\begin{array}{l}161 \\
140\end{array}$ & $\begin{array}{l}94.2 \pm 14.0 \\
91.4 \pm 5.4\end{array}$ & $\begin{array}{l}62 \\
83\end{array}$ & $\begin{array}{l}61.1 \pm 18.3 \\
59.0 \pm 21.2\end{array}$ \\
\hline
\end{tabular}

compared with a total of 8,169 doses on the dose counter (correlation coefficient $=$ 0.981). The differences between the two measures were caused by episodes of multiple priming of the inhaler without inhalation; this was recorded by the dose counter as doses were taken. The mean number of audio files per patient from the 60-dose Diskus inhaler was $48 \pm 10.8$, whereas the mean number of doses recorded from the dose counter was $49 \pm 18.4$.

Analysis of the time-stamped audio data recorded to the INCA device showed errors in inhaler handling, errors in overdosing, and errors in missed doses. The most common critical errors in inhaler use included 308 events (3.1\% of all attempted doses) of low peak inspiratory flow (PIF) and 283 events ( $2.8 \%$ of all attempted doses) of exhalation into the device. Other errors included multiple inhalations with no breath hold and multiple priming of the inhaler without inhalation. The mean technique error rate, $f($ te $)$, was $14.2 \pm$ $21.5 \%$. The mean overdosing rate, $f($ od), was $6.6 \pm 9.2 \%$, and the mean missed doses rate, $f(\mathrm{md})$, was $20.7 \pm 18.7 \%$. Using the AUC method described above and accounting only for evidence of priming of the inhaler, the mean attempted adherence, $f(\mathrm{AT})$, was $79.4 \pm 20.7 \%$. Combined with the technique error rate, this meant that the mean actual adherence, $f(\mathrm{AC})$, at 1 month was $61.8 \pm 28.5 \%$, significantly different from $f(\mathrm{AT})(P<0.01)$ (Table 2 and Figure 3).

INCA and dose counter data. Data for both the dose counter and the INCA device were available for 217 (91\%) of the 239 patients. For these patients, the average dose
A

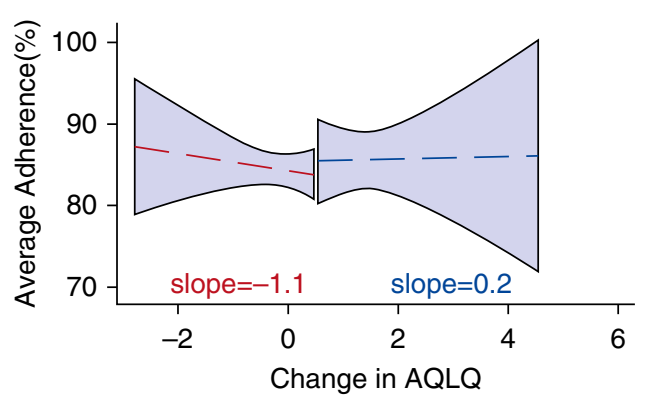

C

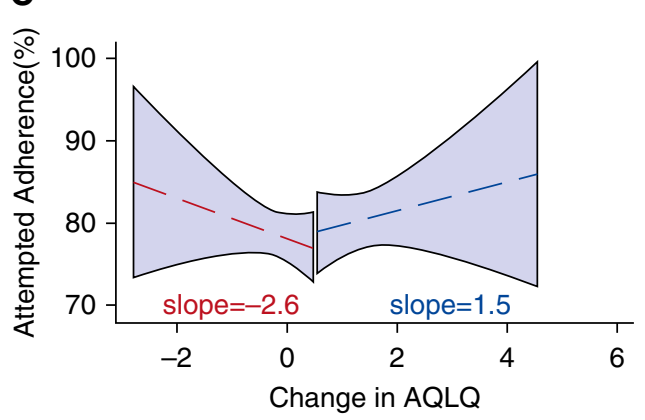

B

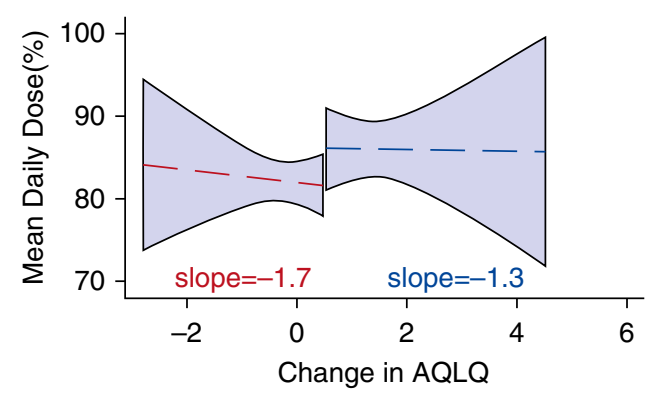

D

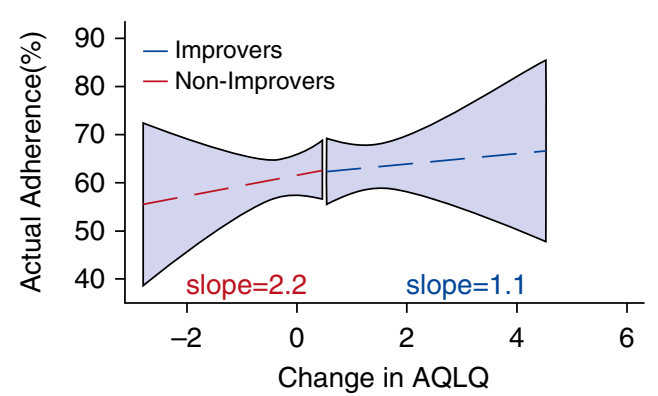

Figure 4. Asthma quality of life (AQLQ) value was recorded on a monthly basis. The minimal clinically important improvement in AQLQ is a 0.5 increase. Patients were divided into those who had a change in AQLQ $\geqslant 0.5$ over 3 months (improvers) and those with a change $<0.5$ over 3 months (nonimprovers). (A) Relationship between the changes in AQLQ and the average adherence calculated from the Diskus dose counter is shown. Using this method of calculation of adherence, paradoxically, nonimprovers had a higher level of adherence than did those who improved. (B) Relationship between the changes in AQLQ and the mean daily dose is shown. Nonimprovers similarly showed no relationship between adherence and change in AQLQ. (C) Relationship between the changes in AQLQ and attempted adherence is shown. Nonimprovers had a higher adherence rate, for a bigger drop in AQLQ, similar to mean daily dose; however, improvers had a better adherence rate as the improvement in AQLQ increased. (D) Relationship between the changes in AQLQ and the actual adherence is shown. Nonimprovers had low adherence rates, which increased as the fall in AQLQ decreased, and improvers had higher adherence rates, which improved as the change in AQLQ increased. There was a significant difference when comparing average adherence (dose counter) with actual adherence and average adherence with attempted adherence $(P<0.01$ and $P<0.03$, respectively). 
counter adherence was $84.4 \pm 19.1 \%$ and the mean daily dose was $85.0 \pm 21.3 \%$.

Using an $80 \%$ cutoff to indicate good adherence, 67 patients (30\%) had good $f(\mathrm{AC})$ over the first month of inhaler use. This was much lower than that calculated using other adherence measures (Table 3 ). As a result, the average adherence, using the dose counter, had $37.1 \%$ sensitivity and $93.0 \%$ specificity, with a $90.2 \%$ positive and a $46.2 \%$ negative predictive value to actual adherence, $f(\mathrm{AC})$ (Table 4$)$.

\section{Associations between Adherence Measures and Clinical Outcomes}

Quality of life. Patient-reported AQLQ change from the start of the monitoring period to the end of the study was analyzed. The coefficient of the regression line for the $f(\mathrm{AC})$ was 1.1 for improvers and 2.2 for nonimprovers, both of which were significantly different from $f(\mathrm{AT})$ $\left(P \leqslant 0.01\right.$ and $r^{2}=0.2$ for nonimprovers) mean daily dose $\left(P \leqslant 0.03\right.$ and $r^{2}=0.7$ for improvers, $P<0.02$ and $r^{2}=0.2$ for nonimprovers), and average adherence $\left(P<0.03\right.$ and $r^{2}=0.7$ for improvers, $P \leqslant 0.02$ and $r^{2}=0.2$ for nonimprovers) (Figure 4).

For the purpose of this analysis, an AQLQ $\geqslant 5$ was considered to be indicative of a good quality-of-life score $(26,27)$. At Month 3, both a good quality-of-life score $($ AQLQ $\geqslant 5)$ and good adherence $(\geqslant 80 \%)$ were seen in $17 \%$ of patients when adherence was calculated by the $f(\mathrm{AC})$ method, compared with 36\% when adherence was calculated using the dose counter (Table 5). In contrast, among those with an AQLQ $<5,35 \%$ had an $f(\mathrm{AC})<80 \%$ and only $16 \%$ had an average dose counter adherence $<80 \%$ $\left(P<0.01, \chi^{2}\right.$ test $)$. The sensitivity and specificity of the various measures of adherence in identifying patients with an improvement in AQLQ are shown in Table 6.

Lung function. The mean (range) variability between morning and evening PEF (A.M. to P.M. variability) was $4.9 \%$ (1-90) in Month 1, 5.6\% (1-85) in Month 2, and $5.0 \%(1-80)$ in Month 3. Compared with the other measures of adherence, $f(\mathrm{AC})$ demonstrated the greatest correlation to A.M. P.M. PEF variability, $\left(P \leqslant 0.03\right.$ and $\left.r^{2}=0.3\right)$ (Figure 5). The sensitivity and specificity of the various measures of adherence in identifying
Table 4. Adherence measures compared with actual adherence

\begin{tabular}{lcccc}
\hline $\begin{array}{l}\text { Adherence } \\
\text { Measure }\end{array}$ & Sensitivity (\%) & Specificity (\%) & PPV (\%) & NPV (\%) \\
$\begin{array}{l}\text { Average adherence } \\
\text { from dose counter }\end{array}$ & 37.1 & 93.0 & 90.2 & 46.2 \\
$\begin{array}{l}\text { Mean daily dose } \\
\text { Attempted adherence }\end{array}$ & 52.8 & 96.6 & 96.4 & 54.1 \\
\hline
\end{tabular}

The table presents the sensitivity, specificity, positive predictive value (PPV), and negative predictive value (NPV) of the dose counter, the mean daily dose, and the attempted adherence in correctly classifying good and poor adherence relative to the actual adherence (using the traditional $80 \%$ cutoff for good adherence). patients with $a \geqslant 10 \%$ improvement in A.M. PEF are shown in Table 6.

$\boldsymbol{\beta}$-Agonist use. Patients who used their short-acting $\beta$-agonist (SABA) every day had a mean $f(\mathrm{AC})$ of $59.0 \pm 30.2 \%$, an average adherence of $83.9 \pm 16.1 \%$, a mean daily dose of $84.7 \pm 19.4 \%$, and a mean attempted adherence of $79.7 \pm 19.5 \%[P<0.01$ when all rates were compared with $f(\mathrm{AC})]$.

\section{Discussion}

Both electronic recording devices and to assess adherence in clinical trials. Traditionally, adherence is judged to be good when the average adherence is $>80 \%$ of expected use. However, there is no scientific basis for assessing adherence as an average value or that $80 \%$ adherence is a valid way of demonstrating good adherence. The purpose of this study was to review some common methods of assessing adherence and to compare these with a proposed new method. The term adherence manual dose counters are commonly used refers to the way that a patient follows the physician's prescription, which is based on the pharmacokinetic principles of the medication. We reasoned that by using the information recorded to the INCA device, which records the time of use and the time between doses, and adjusting for the modifying effect on the dose administered caused by incorrect user technique, we could calculate adherence. To do this, we calculated medication use as an AUC metric, a measure commonly used to reflect plasma drug concentration, and we tested the relationship of this method of calculating adherence to established methods in a cohort of patients with asthma $(18,19)$.

Despite inhaler training, adherence education, and knowingly using an electronic recording device, and despite participating in a clinical trial focused on promoting adherence, episodes of missed doses, overuse, dose dumping, and critical errors in inhaler use were all recorded. As a result, adherence calculated in the proposed manner was significantly lower than that
Table 5. Adherence rates at month 3 and their relationship with changes in $A Q L Q$ and PEF

\begin{tabular}{|c|c|c|c|c|}
\hline \multirow{2}{*}{$\begin{array}{l}\text { Adherence } \\
\text { Measure }\end{array}$} & \multicolumn{2}{|c|}{ PEF } & \multicolumn{2}{|c|}{ AQLQ } \\
\hline & $\begin{array}{c}\text { Improver* } \\
\text { (\%) }\end{array}$ & $\begin{array}{c}\text { Nonimprover } \\
(\%)\end{array}$ & $\begin{array}{l}\text { Improver }^{\dagger} \\
(\%)\end{array}$ & $\begin{array}{c}\text { Nonimprover } \\
(\%)\end{array}$ \\
\hline Actual adherence $f(A C)$ & $68.5 \pm 28.4$ & $65.7 \pm 27.6$ & $66.4 \pm 28.4$ & $64.4 \pm 27.3$ \\
\hline $\begin{array}{l}\text { Average adherence } \\
\text { from dose counter }\end{array}$ & $87.2 \pm 13.0$ & $89.4 \pm 14.5$ & $87.2 \pm 13.8$ & $88.6 \pm 15.3$ \\
\hline Mean daily dose & $84.4 \pm 13.7$ & $84.0 \pm 16.3$ & $83.3 \pm 15.2$ & $83.6 \pm 16.5$ \\
\hline $\begin{array}{l}\text { Attempted adherence } \\
f(\text { AT })\end{array}$ & $81.8 \pm 16.6$ & $82.4 \pm 18.5$ & $82.1 \pm 16.5$ & $80.7 \pm 20.2$ \\
\hline
\end{tabular}

Definition of abbreviations: $\mathrm{AQLQ}=$ Asthma Quality of Life Questionnaire; PEF = peak expiratory flow. ${ }^{*} \geqslant 10 \%$ improvement in A.M. PEF readings.

${ }^{\dagger} \geqslant 0.5$ point improvement in AQLQ. 
Table 6. Receiver operator curve analysis demonstrating the sensitivity and specificity of each adherence measure in correlation to improvements in PEF and AQLQ

\begin{tabular}{|c|c|c|c|c|}
\hline \multirow{2}{*}{$\begin{array}{l}\text { Adherence } \\
\text { Measure }\end{array}$} & \multicolumn{2}{|c|}{ PEF } & \multicolumn{2}{|c|}{ AQLQ } \\
\hline & $\begin{array}{c}\text { Sensitivity } \\
\text { (\%) }\end{array}$ & $\begin{array}{c}\text { Specificity } \\
(\%)\end{array}$ & $\begin{array}{c}\text { Sensitivity } \\
(\%)\end{array}$ & $\begin{array}{c}\text { Specificity } \\
(\%)\end{array}$ \\
\hline Actual adherence $f(A C)$ & 59.8 & 46.9 & 66.7 & 44.6 \\
\hline $\begin{array}{l}\text { Average adherence } \\
\text { from dose counter }\end{array}$ & 19.5 & 71.9 & 19.2 & 73.7 \\
\hline Mean daily dose & 27.1 & 69.7 & 25.0 & 73.3 \\
\hline Attempted adherence $f($ AT $)$ & 32.5 & 63.6 & 37.5 & 66.0 \\
\hline
\end{tabular}

Definition of abbreviations: AQLQ = Asthma Quality of Life Questionnaire; PEF = peak expiratory flow.

quantified by other commonly used methods, such as mean adherence (28-31) or the mean daily dose $(2,32)$.

Over a 3-month period in which adherence, AQLQ, ACT, PEF, and inhaled $\beta$-agonist use were quantified, only actual adherence $[f(\mathrm{AC})]$ reflected the changes in patient outcomes. In contrast, average adherences calculated from the dose counter, the mean daily dose, and the attempted adherence $[f(\mathrm{AT})]$ all failed to distinguish between those who did and did not have clinically meaningful improvements in several related clinical measures. For example, an inverse relationship was found for nonimprovers, between the currently used measures of adherence and changes in AQLQ. In addition, PEF correlated only with $f(\mathrm{AC})$, with less morning-to-evening variability in
PEF associated with higher levels of $f(\mathrm{AC})$. Likewise, significantly higher $\beta$-agonist reliever use was associated with lower $f(\mathrm{AC})$. These relationships were not seen with other measures of adherence. These results demonstrate the importance of variation in the time of use and errors in inhaler handling and emphasize the need to incorporate this information into the calculation of adherence.

\section{Limitations}

This study has several limitations. First, the patients studied had already been prescribed inhaled salmeterol/fluticasone for some time. Hence, it is not too surprising that there were relatively small changes in lung function and quality of life. Furthermore, the duration of follow-up was relatively short and possibly not of sufficient duration to see more significant correlations with clinical parameters (33). Nonetheless, the novel measurement of adherence that we have described demonstrated significant associations with several measures of asthma over the timeframe, demonstrating
A

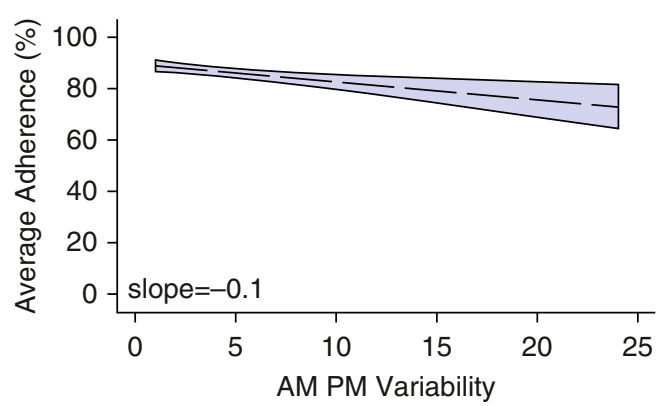

C

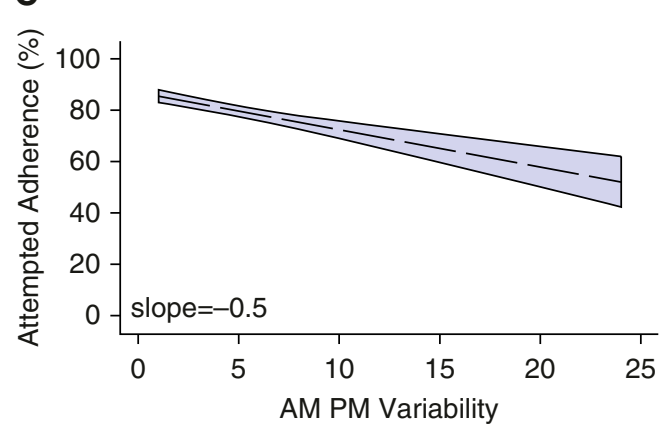

B

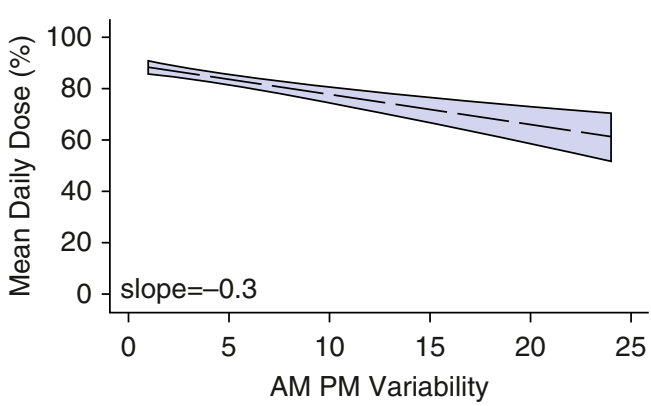

D

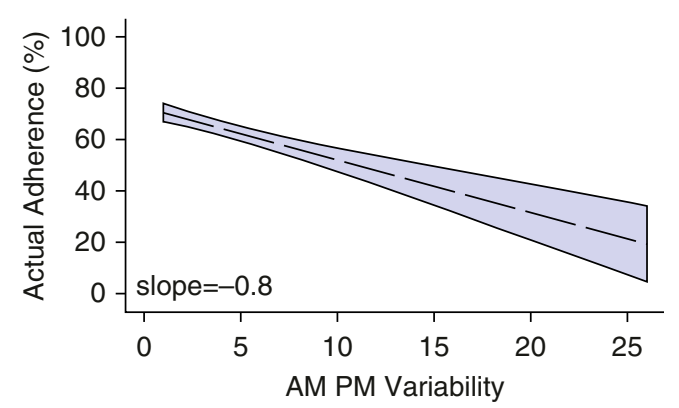

Figure 5. Twice-daily peak expiratory flow (PEF) was divided into morning (A.M.) and evening (P.M.) readings. The mean variability between the A.M. and the P.M. readings was calculated for each month for each patient. (A-D) Change in A.M.-P.M. PEF variability for the four measures of adherence, $(A)$ average adherence calculated from the dose counter, $(B)$ the mean daily dose, $(C)$ attempted adherence $[f(A T)]$ and $(D)$ actual adherence $[f(A C)]$. actual adherence $[f(\mathrm{AC})]$ showed the most negative relationship with A.M.-P.M. PEF variability (slope, -0.8$)$. There was a significant difference between average adherence with both $f(\mathrm{AC})$ and $f(\mathrm{AT}) \quad(P=0.01$ and $P=0.03$, respectively). 
its appropriateness. Future experimental tests of the approach described here will involve testing in larger populations and for longer periods of time.

We have previously described the close relationship of acoustically assessed PIF with objectively measured PIF $(14,16,17)$. We have also described the significant effect of both low PIF and that of exhalation into the inhaler on drug delivery $(14,16,17,34)$. For the purpose of calculating the impact of inhaler technique errors on adherence, we used a binary response (present/not present), but different degrees of user errors will have different impacts on drug delivery, and this will need to be further evaluated and incorporated into this method of calculating adherence (14-17). Adherence and nonadherence to an intervention has serious and obvious implications for a clinical trial. Variations in adherence influence the statistical power of a study and the effect size of different therapies and have serious implications for estimates of the incidence of adverse events. In addition, knowing the adherence of a therapy in a clinical trial can provide insight into patient acceptability of a new treatment or new inhaler device. The results of this study highlight the limited sensitivity of the currently used method of describing adherence as a mean value.

The approach for calculation of actual adherence $[f(\mathrm{AC})]$ described here would be useful for clinical trials involving a diverse range of respiratory conditions, including those requiring inhaled antibiotics or other agents, where errors in timing or user technique may directly affect drug accumulation. This may also be important in phase 2 studies in which adjustment for patients achieving per protocol adherence may help avoid type 2 errors in data analysis.

\section{Conclusions}

We have developed a method of calculating inhaler adherence modeled on the concepts of drug pharmacokinetics that incorporates both the time of use of an inhaler and the technique used. This method not only identifies which component of adherence is deficient but is also more reflective of the clinical changes expected from a medication than are the current methods used to assess adherence.

Author disclosures are available with the text of this article at www.atsjournals.org.

Acknowledgment: The authors thank the Health Research Board and GlaxoSmithKline Global (Evan Daly, Martijn Akveld, Raj Sharma, and Dr. David Leather).

\section{References}

1 Farmer KC. Methods for measuring and monitoring medication regimen adherence in clinical trials and clinical practice. Clin Ther 1999;21: 1074-1090, discussion 1073.

2 Patel M, Pilcher J, Pritchard A, Perrin K, Travers J, Shaw D, Holt S, Harwood M, Black P, Weatherall M, et al.; SMART Study Group: Efficacy and safety of maintenance and reliever combination budesonide-formoterol inhaler in patients with asthma at risk of severe exacerbations: a randomised controlled trial. Lancet Respir Med 2013;1:32-42.

3 Perrin K, Williams M, Wijesinghe M, James K, Weatherall M, Beasley R. Randomized controlled trial of adherence with single or combination inhaled corticosteroid/long-acting beta-agonist inhaler therapy in asthma. J Allergy Clin Immunol 2010;126:505-510.

4 Foster JM, Usherwood T, Smith L, Sawyer SM, Xuan W, Rand CS, Reddel HK. Inhaler reminders improve adherence with controller treatment in primary care patients with asthma. $J$ Allergy Clin Immunol 2014;134:1260-1268.e3.

5 Lavorini F, Magnan A, Dubus JC, Voshaar T, Corbetta L, Broeders M, Dekhuijzen R, Sanchis J, Viejo JL, Barnes P, et al. Effect of incorrect use of dry powder inhalers on management of patients with asthma and COPD. Respir Med 2008;102:593-604.

6 Capanoglu M, Dibek Misirlioglu E, Toyran M, Civelek E, Kocabas CN. Evaluation of inhaler technique, adherence to therapy and their effect on disease control among children with asthma using metered dose or dry powder inhalers. J Asthma 2015;52:838-845.

7 Basheti IA, Bosnic-Anticevich SZ, Armour CL, Reddel HK. Checklists for powder inhaler technique: a review and recommendations. Respir Care 2014;59:1140-1154.

8 Al-Jahdali H, Ahmed A, Al-Harbi A, Khan M, Baharoon S, Bin Salih S, Halwani R, Al-Muhsen S. Improper inhaler technique is associated with poor asthma control and frequent emergency department visits. Allergy Asthma Clin Immunol 2013;9:8.

9 Press VG, Arora VM, Shah LM, Lewis SL, Ivy K, Charbeneau J, Badlani S, Nareckas E, Mazurek A, Krishnan JA. Misuse of respiratory inhalers in hospitalized patients with asthma or COPD. J Gen Intern Med 2011;26:635-642.

10 Melani AS, Bonavia M, Cilenti V, Cinti C, Lodi M, Martucci P, Serra M, Scichilone N, Sestini P, Aliani M, et al.; Gruppo Educazionale Associazione Italiana Pneumologi Ospedalieri. Inhaler mishandling remains common in real life and is associated with reduced disease control. Respir Med 2011;105:930-938. [Published erratum appears in Respir Med 106:757.]

11 Wieshammer S, Dreyhaupt J. Dry powder inhalers: which factors determine the frequency of handling errors? Respiration 2008;75: 18-25.

12 Cochrane MG, Bala MV, Downs KE, Mauskopf J, Ben-Joseph RH. Inhaled corticosteroids for asthma therapy: patient compliance, devices, and inhalation technique. Chest 2000;117:542-550.

13 D'arcy S, MacHale E, Seheult J, Holmes MS, Hughes C, Sulaiman I, Hyland D, O'Reilly C, Glynn S, Al-Zaabi T, et al. A method to assess adherence in inhaler use through analysis of acoustic recordings of inhaler events. PLoS One 2014;9:e98701.

14 Holmes MS, Seheult JN, Geraghty C, D'Arcy S, O’Brien U, Crispino O'Connell G, Costello RW, Reilly RB. A method of estimating inspiratory flow rate and volume from an inhaler using acoustic measurements. Physiol Meas 2013;34:903-914.

15 Holmes MS, D'arcy S, Costello RW, Reilly RB. Acoustic analysis of inhaler sounds from community-dwelling asthmatic patients for automatic assessment of adherence. IEEE J Transl Eng Health Med 2014;2:2700210.

16 Seheult JN, Costello S, Tee KC, Bholah T, Al Bannai H, Sulaiman I, Costello RW. Investigating the relationship between peak inspiratory flow rate and volume of inhalation from a Diskus ${ }^{\mathrm{TM}}$ Inhaler and baseline spirometric parameters: a cross-sectional study. Springerplus 2014;3:496.

17 Seheult JN, O'Connell P, Tee KC, Bholah T, Al Bannai H, Sulaiman I, MacHale E, D'Arcy S, Holmes MS, Bergin D, et al. The acoustic features of inhalation can be used to quantify aerosol delivery from a Diskus $^{\mathrm{TM}}$ dry powder inhaler. Pharm Res 2014;31:2735-2747.

18 Sulaiman I, Seheult J, Killane I, MacHale E, Reilly R, Costello R. A new clinically relevant method of calculating adherence [abstract]. Eur Respir J 2015;46:3932.

19 Sulaiman I, Mac Hale E, Holmes M, Hughes C, D'Arcy S, Taylor T, Rapcan V, Doyle F, Breathnach A, Seheult J, et al. A protocol for a randomised clinical trial of the effect of providing feedback on inhaler technique and adherence from an electronic device in patients with poorly controlled severe asthma. BMJ Open 2016;6:e009350.

20 Long D, Lyons AM, Byrne T, Coatello R. Impact of a new inhaler management policy on the hospitalised patient [abstract]. Eur Respir J 2014;44:1299.

21 Long D, Lyons AM, Byrne T, Sulaiman I, Costello R. Inhaler proficiency following the introduction of a new inhaler management policy for hospitalised patients [abstract]. Eur Respir J 2014;44:1298. 
22 Mac Hale E, Costello RW, Cowman S. A nurse-led intervention study: promoting compliance with Diskus Inhaler use in asthma patients. Nurs Open. 2014;1:42-52.

23 Bousquet J, Clark TJ, Hurd S, Khaltaev N, Lenfant C, O'byrne P, Sheffer A. GINA guidelines on asthma and beyond. Allergy 2007;62: 102-112.

24 Global Initiative for Asthma. At-a-glance asthma management reference [updated 2014; accessed January 1, 2016]. Available from: http://ginasthma.org/wp-content/uploads/2016/01/ GINA AtAGlance_2014.pdf

25 Thiadens HA, De Bock GH, Dekker FW, Huysman JA, Van Houwelingen JC, Springer MP, Postma DS. Value of measuring diurnal peak flow variability in the recognition of asthma: a study in general practice. Eur Respir J 1998;12:842-847.

26 Juniper EF, Guyatt GH, Willan A, Griffith LE. Determining a minimal important change in a disease-specific Quality of Life Questionnaire. $J$ Clin Epidemiol 1994;47:81-87.

27 Juniper EF, Guyatt GH, Epstein RS, Ferrie PJ, Jaeschke R, Hiller TK. Evaluation of impairment of health related quality of life in asthma: development of a questionnaire for use in clinical trials. Thorax 1992; 47:76-83.

28 Choo PW, Rand CS, Inui TS, Lee MT, Canning C, Platt R. Derivation of adherence metrics from electronic dosing records. J Clin Epidemiol 2001;54:619-626. (Internet).
29 Osterberg L, Blaschke T. Adherence to medication. N Engl J Med 2005; 353:487-497.

30 Blaschke TF, Osterberg L, Vrijens B, Urquhart J. Adherence to medications: insights arising from studies on the unreliable link between prescribed and actual drug dosing histories. Annu Rev Pharmacol Toxicol 2012;52:275-301.

31 Zhang Z, Peluso MJ, Gross CP, Viscoli CM, Kernan WN. Adherence reporting in randomized controlled trials. Clin Trials 2014;11: 195-204.

32 Charles T, Quinn D, Weatherall M, Aldington S, Beasley R, Holt S. An audiovisual reminder function improves adherence with inhaled corticosteroid therapy in asthma. J Allergy Clin Immunol 2007;119: 811-816.

33 Bateman ED, Boushey HA, Bousquet J, Busse WW, Clark TJH, Pauwels RA, Pedersen SE; GOAL Investigators Group. Can guideline-defined asthma control be achieved? The Gaining Optimal Asthma ControL study. Am J Respir Crit Care Med 2004;170: 836-844.

34 Holmes MS, Seheult JN, O'Connell P, D’Arcy S, Ehrhardt C, Healy AM, Costello RW, Reilly RB. An acoustic-based method to detect and quantify the effect of exhalation into a dry powder inhaler. $J$ Aerosol Med Pulm Drug Deliv 2015;28:247-253. 